\title{
A new kind of epistemic indefinite ${ }^{1}$
} Virginia DAWSON - University of California, Berkeley

\begin{abstract}
Tiwa (Tibeto-Burman; India) has two series of epistemic indefinites: one whose epistemic effects arise via an anti-singleton constraint similar to Spanish algún (Alonso-Ovalle and Menéndez-Benito, 2010), and another, wide-scope indefinite whose epistemic effects must be derived differently. I propose that for these latter indefinites, ignorance arises not through domain constraints, but as a result of their choice functional nature through competition with other indefinites. Tiwa's wide scope indefinites then constitute a new kind of epistemic indefinite, showing that ignorance implicatures for indefinites can arise through different sorts of competition.
\end{abstract}

Keywords: epistemic indefinites, wide scope indefinites, choice functions, implicature, Tiwa.

\section{Introduction}

Epistemic indefinites are indefinite pronouns and determiners that convey that the speaker is ignorant with respect to the witness to that indefinite (Alonso-Ovalle and Menéndez-Benito, 2015). An example of this is Spanish algún (Alonso-Ovalle and Menéndez-Benito, 2010). ${ }^{2}$ When speakers use algún in non-downward-entailing environments, they convey that they are ignorant with respect to the identity (or number) of the witness. Alonso-Ovalle and MenéndezBenito (2010) attribute these epistemic effects to a conversational implicature that arises due to the domain requirements of algún. Specifically, algún places an anti-singleton requirement on its domain: it cannot range over a singleton set. Adopting the neo-Gricean analysis that Kratzer and Shimoyama (2002) propose for similar effects with German irgendein, ${ }^{3}$ AlonsoOvalle and Menéndez-Benito derive the epistemic effects of algún as a quantity implicature that arises through avoidance of a false exhaustivity inference. Specifically, in using an indefinite that ranges over a non-singleton domain, the speaker makes a weaker statement than if she used a singleton competitor. From this, the hearer reasons that the speaker did so to avoid implying that she believes some of the alternatives are false (through an exhaustivity inference). The hearer concludes that the speaker does not know that some of these alternatives are false, which

\footnotetext{
${ }^{1}$ Thanks to Mary and Bibiana Maslai, and the rest of the Tiwa community of Umswai for sharing their language with me. Thanks also to Amy Rose Deal, Line Mikkelsen, Seth Yalcin, Peter Jenks, Sarah Murray, and audiences at TripleA 4, Sinn und Bedeutung 22, NELS 48, and UCSC's S-Circle for comments, suggestions, and feedback. Any errors are mine alone. This research was made possible by two Oswalt Endangered Languages grants.

${ }^{2}$ Other epistemic indefinites that have been discussed in the literature include German irgendein (Kratzer and Shimoyama, 2002), Italian un qualsiasi (Aloni and van Rooij, 2004; Chierchia, 2006) and un qualche (Zamparelli, 2007), French quelque and un quelconque (Jayez and Tovena, 2006, 2007), the Russian -to series (Kagan, 2011), Romanian vreun (Farkas, 2002; Fălăuş, 2014), the Japanese -ka series (Alonso-Ovalle and Shimoyama, 2014), and the Czech -si series (Šimík, 2015). Note that not all epistemic effects associated with indefinites have been analyzed as conversational implicatures.

${ }^{3}$ German irgendein conveys speaker ignorance or indifference with respect to the witness. The domain requirements irgendein places are different from those of algún: instead of simply requiring a non-singleton domain, irgendein is a domain widener. This difference manifests in its epistemic component: irgendein requires that the speaker be ignorant with respect to the entire domain, while algún allows for ignorance with respect to a subset of the domain.
} 
results in the ignorance implicature.

Tiwa, a Tibeto-Burman language of India, ${ }^{4}$ has two distinct series of epistemic indefinites, whose epistemic effects, I will argue, arise pragmatically. These are the -khi series and the -pha series, illustrated in (1) and (2) respectively. ${ }^{5}$ In both cases, it is infelicitous for the speaker to use a -khi or - pha indefinite and then identify the witness: in using these indefinites, the speaker has conveyed ignorance.

(1) Shar-khí phi-dom. \# Pe-do Mukton.

who-KHI come-PST 3SG-TOP Mukton

'Someone came. \# Namely, Mukton.' [2017.1.81]

(2) Shar-pha phi-dom. \# Pe-do Mukton.

who-PHA come-PST 3SG-TOP Mukton

'Someone came. \# Namely, Mukton.' [2017.1.81]

These indefinites contrast with the plain, non-epistemic indefinite, the numeral "one", which can be felicitously followed with an explicit identification of the witness. This is shown in (3).

Sája líbing phi-dom. Pe-do Mukton.

one.CL person come-PST 3SG-TOP Mukton

'A person came. Namely, Mukton.' [2017.1.81]

In this paper, I show that the epistemic effects associated with both -khi and -pha indefinites in Tiwa arise as conversational implicatures, but that they must arise in different ways. In particular, the epistemic effects associated with -pha arise as a consequence of its anti-singleton domain requirements, similar to Spanish algún. In contrast, the epistemic effects of $-k h i$, a wide scope choice functional indefinite, arise not through domain requirements, but as a result of the indefinite's choice functional nature. Tiwa's - $k h i$ indefinites then constitute a new kind of epistemic indefinite, one whose epistemic effects are pragmatic, but do not arise as a consequence of domain requirements.

The paper is structured as follows. In $\S 2$ I show that the ignorance effects associated with $-k h i$ and - pha indefinites behave like a conversational implicature. ${ }^{6}$ In $\S 3$ I propose an analysis for -pha indefinites following that proposed by Alonso-Ovalle and Menéndez-Benito (2010) for

\footnotetext{
${ }^{4}$ Tiwa is spoken by approximately 27,100 people primarily in west Karbi Anglong district, Assam, India (2001 estimates; Simons and Fennig 2017). The data used here were collected by the author in Umswai, Karbi Anglong over the course of two summers (2016 and 2017).

${ }^{5}$ Examples are presented in the orthography used in Joseph's (2014) dictionary. A reference to year, notebook number, and page are given to the right of each translation. Abbreviations are: ACC 'accusative', ADD 'scalar additive', AUX 'auxiliary', CF 'counterfactual', CL 'classifier', COM 'comitative', COMP 'complementizer', COND 'conditional', COP 'copula', DAT 'dative', GEN 'genitive', INF 'infinitive', IPFV 'imperfective', NEG 'negation', NEUT 'neutral aspect', NMLZ 'nominalizer', PFV 'perfective', PL 'plural', PST 'past', SG 'singular', TOP 'topic'. ${ }^{6}$ Not every epistemic indefinite discussed in the literature has been analyzed as involving conversational implicature. Aloni and Port (2015), for example, argue that the epistemic component of such indefinites is better analyzed as a felicity condition. See Alonso-Ovalle and Menéndez-Benito 2013 for a summary and comparison of the two main approaches to epistemic indefinites.
} 
Spanish algún. In $\S 4$ I turn to Tiwa's -khi indefinites, demonstrating that they show exceptional wide scope, and proposing a choice functional analysis with existential closure that accounts for this. I also show why Alonso-Ovalle and Menéndez-Benito's analysis cannot be extended to $-k h i$ indefinites. In $\S 5$ I discuss the range of epistemic readings available to - $k h i$ indefinites and suggest that their epistemic effects result from existential quantification over choice functions, through competition with indefinite and definite alternatives. I conclude in $\S 6$, and consider the crosslinguistic implications of this analysis.

\section{Epistemic indefinites in Tiwa}

Tiwa's two series of epistemic indefinites are formed through suffixation of either - pha or -khi to an indeterminate base, glossed as a $w h$-word throughout. (In its bare form, the indeterminate base functions as a wh-word.) These indefinites can function either as an article, or as an independent pronoun. For an analysis of the internal composition of these indefinites, and discussion of Tiwa's indeterminates more generally, see Dawson to appear.

\begin{tabular}{|c|c|c|}
\hline \multicolumn{3}{|c|}{ Tiwa's epistemic indefinites } \\
\hline base gloss & $-k h i$ & -pha \\
\hline who & shar-khí ${ }^{7}$ & shar-pha \\
\hline what & inda-khí & inda-pha \\
\hline where & pajíng-khî & pajíng-phâ \\
\hline where & pathô-khi & pathô-pha \\
\hline when & pakhál-khî & pakhál-phâ \\
\hline how & padi-khí & padî-pha \\
\hline how much & pasí-khî & - \\
\hline which & pakhâ-khi & pakhâ-pha \\
\hline
\end{tabular}

As shown in $\S 1$, both - $p h a$ and $-k h i$ indefinites cannot be felicitously followed by an identification of the witness (examples (1) and (2)), in contrast to the plain indefinite (example (3)). This infelicity is due to the fact that both - pha and -khi indefinites strongly convey speaker ignorance with respect to the witness. In both cases, this ignorance arises as a conversational implicature: the effects can be cancelled, reinforced, and, in the case of -pha indefinites, it disappears in downward-entailing environments.

\subsection{Conversational implicature}

The epistemic effects associated with both - pha and -khi indefinites behave like a conversational implicature. The first piece of evidence for this is that in both cases the implication of speaker ignorance can be canceled if there is some other reason to use an indefinite (e.g., if the speaker does not want to identify the witness). This is shown for -pha in (5) and (6). In both examples, the speaker follows an assertion with a -pha indefinite by explicitly stating that she can identify the witness.

\footnotetext{
${ }^{7}$ In addition to the morphologically transparent form shar-khí, there are various allomorphs for the human -khi indefinite, including sharkhine, shargíne, sharkhídi, and shagídi (see Joseph 2014).
} 
(5) Maria shar-pha-go lak mán-ga, arô shar-go ang si-w.

Maria who-PHA-ACC meet-PFV and who-ACC 1SG know-NEUT

'Maria met someone, and I know who.' [2016.1.88]

(6)

Shar-pha phi-dom. Ang pro $_{i}$ si-w, thêbo ná pro pri-ya.

who-PHA come-PST 1SG 3SG know-NEUT but 2SG 3SG know-NEG

'Someone came. I know him, but you don't.' [2016.2.41]

Cancelation for -khi is shown in (7) and (8). In (7), the speaker knows who she will marry, but does not want to tell the addressee who it is. The preceding context of (8) is that there is a man who is constantly bothering the speaker, which includes always asking her invasive questions about her recent activities. The speaker replies to a question about when she went to Guwahati, with the sentence in (8): she is explicitly withholding information.

Ang shar-khí-na-rê phadé-w, thêbo ang sóng-ya shar-a-re.

$1 \mathrm{SG}$ who-KHI-DAT-COM marry-NEUT but $1 \mathrm{SG}$ tell-NEG who-DAT-COM

'I'm going to marry someone, but I won't tell you who.' [2017.1.84]

$$
\begin{aligned}
& \text { Pakhál-khî lí-dom. Ang si-w pakhál, thêbo nága sóng os-ya. } \\
& \text { when-KHI go-PST 1 SG know-NEUT when but 2SG.DAT tell AUX-NEG } \\
& \text { 'I went sometime. I know when, but I won't tell you.' [2017.2.7] }
\end{aligned}
$$

Note that the ignorance implicature for - $k h i$ indefinites is harder to cancel than it is for - pha indefinites. While the ignorance component of -pha can be canceled by simply adding "I know who" as shown in (5), this same strategy is judged infelicitous for -khi:

(9) Maria shar-khí-gô lak mán-ga, \# arô shar-go ang si-w.

Maria who-KHI-ACC meet-PFV and who-ACC 1 SG know-NEUT

'Maria met someone, \# and I know who.' [2016.1.88]

In addition to cancelation, the ignorance component of both series of indefinites can be reinforced without redundancy, showing that ignorance is not part of the asserted content. Reinforcement is shown for - pha in (10) and for -khi in (11).

(10) Maria shar-pha-go lak mán-ga, thêbo shar-go ang si-ya.

Maria who-PHA-ACC meet-PFV but who-ACC 1 SG know-NEG

'Maria met someone, but I don't know who.' [2016.1.88]

(11) Maria shar-khí-gô lak mán-ga, thêbo shar-go ang si-ya.

Maria who-KHI-ACC meet-PFV but who-ACC 1SG know-NEG

'Maria met someone, but I don't know who.' [2016.1.88]

A type of evidence for conversational implicature comes from behavior in downward-entailing contexts: when an epistemic indefinite scopes under negation or a conditional operator, for example, the epistemic effect is lost. This is shown for negation in (12) and for a conditional in (13). In these two sentences, which feature - pha indefinites, there is no epistemic effect. 
(Indeed, it is difficult to imagine what an epistemic effect would look like when the indefinite is in a downward-entailing context, such as embedded under negation or a conditional operator.)

$$
\begin{aligned}
& \text { [CP Shar-pha phi-dom honmandé ] thángane cha. } \\
& \text { who-PHA come-PST COMP correct NEG } \\
& \text { 'It's not correct that someone came.' [2016.2.42] } \\
& \checkmark \text { : Nobody came. }
\end{aligned}
$$

(13) Chidî shar-pha sister lak mán-a phi-gaido, Saldi khúp khâdu-gam. if who-PHA sister meet-INF come-COND Saldi very happy-CF 'If Saldi meets some nun, she would be very happy.' [2016.1.131] $\checkmark$ : Meeting any nun will make Saldi happy.

Note, though, that this test cannot be applied to $-k h i$ indefinites, since they necessarily take wide scope over all other operators, including from inside islands. I return to this point in $\S 4$.

\section{3. -pha indefinites}

In the previous section, I showed that the speaker ignorance component associated with both $-k h i$ and -pha indefinites behaves like a canonical conversational implicature: it is cancelable and reinforceable, and, in the case of -pha indefinites, disappears in downward-entailing environments. In this section, show that just like Spanish algún, -pha indefinites must range over a non-singleton domain. I propose that Alonso-Ovalle and Menéndez-Benito's (2010) analysis be extended to - pha indefinites.

\section{1. - pha indefinites have an anti-singleton constraint}

Tiwa's - pha indefinites have an anti-singleton constraint, similar to the one described for Spanish algún (Alonso-Ovalle \& Menéndez-Benito 2010). This is most clearly illustrated in the contrast between (14) and (15), in which an indefinite combines with the restrictor 'pope'. There is only one pope; the extension of Pha Khûmur is a singleton. The plain indefinite, which has no domain restrictions, is felicitous in such cases, as shown in (14), while -pha indefinites are infelicitous, as shown in (15).

(14) Ang sája Pha Khûmur-go lak mán-a lí-do.

1SG one.CL father holy-ACC meet-INF go-IPFV

'I'm going to meet a pope.' [2017.1.29]

(15) \#Ang shar-pha Pha Khûmur-go lak mán-a lí-do.

$1 \mathrm{SG}$ who-PHA father holy-ACC meet-INF go-IPFV

Intended: 'I'm going to meet some pope.' [2017.1.29]

Comment: Because Pha Khûmur is only one.

Note the absence of an anti-uniqueness effect for the plain indefinite (and also - $k h i$ indefinites; see $\S 4$ ), which we might have expected to arise through Maximize Presupposition in competi- 
tion with the definite (Heim, 1991). If -pha indefinites carry an anti-singleton presupposition, as I propose below, the absence of this effect is expected: in using the plain indefinite, rather than the definite, the speaker has failed to presuppose that there is a unique referent. However, the speaker has also failed to employ the anti-singleton presupposition associated with the -pha indefinite. These presuppostions effectively cancel each other out, leaving the plain indefinite neutral with respect to its likely domain.

Further evidence for an anti-singleton constraint on - pha indefinites comes from examples like (16). This example was deemed infelicitous in an out of the blue context, where the extension of Indiane PM is understood to be the singleton set $\{$ Modi\}. It becomes grammatical, however, in a context in which all living Indian prime ministers, past and present, are relevant: the domain is no longer a singleton.

Ang shar-pha India-ne PM-go lak mán-a lí-do.

$1 \mathrm{SG}$ who-PHA India-GEN PM-ACC meet-INF go-IPFV

'I'm going to meet some Indian Prime Minister.' [2016.2.101]

\#: Out of the blue (there is only one PM: Modi)

$\checkmark$ : All past and present Indian PMs are contextually relevant (Modi, Singh, ...)

An anti-singleton constraint on - pha also straighforwardly explains the only gap found in the -khi and -pha series as outlined in the table in (4). Specifically, there is no -pha indefinite corresponding to the indeterminate pasi 'how much'. If pasí picks out the maximal degree to which some property holds of an individual, this gap is explained: as there can only be one maximal degree, it follows that anti-singleton pasí-phâ would be an anomaly.

\subsection{Deriving - $p h a$ 's epistemic effect}

Tiwa's - pha indefinites are similar to Spanish algún, which likewise has an anti-singleton constraint, and whose epistemic effects are a conversational implicature (Alonso-Ovalle and Menéndez-Benito, 2010). Accordingly, I propose to treat -pha indefinites in the same way as algún. Specifically, -pha indefinites carry a condition that their domain is not a singleton, as formalized in (17) following Alonso-Ovalle and Menéndez-Benito 2010.

$$
\llbracket \text { Wh-pha } \rrbracket=\lambda f_{\langle e t, e t\rangle} \cdot \lambda P_{\langle e t\rangle} \cdot \lambda Q_{\langle e t\rangle}: \text { anti-singleton }(f) . \exists x[f(P)(x) \& Q(x)]
$$

When a speaker uses a -pha indefinite in an upward entailing environment, she necessarily makes a weaker statement than she would if she used a singleton alternative, such as a definite description, a name, or an indefinite that allows for a singleton domain. Consider the sentence in (18a). ${ }^{8}$

$$
\begin{aligned}
& \text { a. Maria shar-pha sister-go lak mán-ga. } \\
& \text { Maria who-PHA nun-ACC meet-PFV }
\end{aligned}
$$

\footnotetext{
${ }^{8}$ I follow Kratzer and Shimoyama (2002) and Alonso-Ovalle and Menéndez-Benito (2010) in assuming a covert assertoric operator represented by $\square$.
} 
'Maria met some nun.' [2016.2.63]

b. Assertion: $\square[\exists x[f(\operatorname{nun})(x) \& \operatorname{meet}($ Maria $)(x)]]$

c. Presupposition: $\mid f($ nun $) \mid>1$

In using sharpha sister, the speaker has explicitly signaled that the domain is a non-singleton, perhaps consisting of a set of three individuals \{Lily, Irene, Filina $\}$. By using sharpha sister in this case, the speaker is asserting that Maria met someone in that domain, as in (19a). But she could have asserted that Lily came, or that Irene came, or that Filina came. The hearer reasons that she did so to avoid a false claim: it's not the case that Maria must have met Lily, and so on. This gives rise to the implicature in (19b): the speaker cannot truthfully make a stronger assertion because she doesn't know if it's true.

$$
\begin{aligned}
& \text { a. } \quad \square[\text { met(Lily)(Maria) } \vee \operatorname{met}(\text { Irene })(\text { Maria }) \vee \operatorname{met}(\text { Filina)(Maria) }] \\
& \text { b. } \quad \neg \square[\text { met(Lily)(Maria) }] \& \neg \square[\text { met(Irene)(Maria) }] \& \neg \square[\text { met(Filina)(Maria) }]
\end{aligned}
$$

Kratzer and Shimoyama (2002) and Alonso-Ovalle and Menéndez-Benito (2010) show that a different pragmatic reasoning must take place under possibility modals to derive the ignorance implicature, since one of the singleton alternatives is necessarily true. They propose that in these cases, the hearer reasons that the speaker has used the non-singleton alternative to avoid a false exhaustivity inference. Specifically, a stronger singleton alternative under a possibility modal would lead the hearer to draw an exhaustivity inference $(\diamond p$ implies $\neg \diamond q)$. The hearer reasons that the speaker is avoiding this inference by using a non-singleton: neither $\diamond \mathrm{p}$ nor $\diamond \mathrm{q}$ are ruled out. Again this implicates speaker ignorance. See Kratzer and Shimoyama (2002) and Alonso-Ovalle and Menéndez-Benito (2010) for more detailed discussion of this analysis.

Importantly, the ignorance implicatures disappear in downward entailing environments such as negation and conditionals, because in using an indefinite with a non-singleton domain the speaker has made a stronger statement. The analysis sketched above derives the epistemic effects of - pha indefinites from an independent fact of their semantics (that they require a nonsingleton domain), and explains why the effects are cancelable and disappear in downward entailing environments. The Tiwa data provides another clear example of an anti-singleton indefinite that has exactly the behaviors expected of such an indefinite.

\section{4. -khi as a wide scope indefinite}

Tiwa's - pha indefinites are generalized existential quantifiers: they can scope above or below other operators, and resist scoping out of islands (possibly due to their antisingleton constraint (Schwarzschild, 2002)), as shown below in (26) and (27). Tiwa's -khi indefinites, in contrast, take obligatory wide scope over all other operators, including from inside islands. Examples (20)-(23) show wide scope with respect to clausemate negation, a universal quantifier, a deontic necessity modal, and an attitude verb, respectively.

(20) Maria inda-khí kashóng pre-ya-m.

Maria what-KHI dress buy-NEG-PST

'Maria didn't buy some dress.' [2016.1.130]

$\checkmark$ : There's a particular unknown dress Maria didn't buy. 
\#: There were no dresses.

$* \neg>\exists$

(21)

Sogól-lô inda-khí hat-a lí-ga.

everyone-FOC what-KHI market-DAT go-PFV

'Everyone went to some market.' [2016.1.133]

$\checkmark$ : Everyone went to a particular, unknown market. $\quad \exists>\forall$

\#: Each person went to a different market.

$* \forall>\exists$

(22) Maria shar-khí sister-go lak mán-a mán-o.

Maria who-KHI sister-ACC meet-INF must-NEUT

'Maria has to meet some nun.' [2016.2.52]

$\checkmark$ : There is a particular nun, unknown to the speaker, that Maria has to meet. $\exists>$

\#: Maria needs to meet with any nun.

$* \square>\exists$

Ang [ shar-khí Delhi-jíng shó-wa mewâ-go ]DP pháde-na hal-do.

$1 \mathrm{SG}$ who-KHI Delhi-ALL reach-NMLZ man-ACC marry-INF want-IPFV

'I want to marry some man that's been to Delhi.' [2016.2.120]

$\checkmark$ : The speaker saw him the other day, but hasn't actually met him. $\quad \exists>$ want

\#: The speaker wants to marry any man that's been to Delhi. * want $>\exists$

Examples (24) and (25) show that -khi indefinites must scope out of islands, shown here with a finite embedded clause and a conditional antecedent, respectively. ${ }^{9}$

(24) [ Shar-khí phi-dom honmandé $]_{\mathrm{CP}}$ thángane cha.

who-PHA come-PST COMP correct NEG

'It's not correct that someone came.' [2016.2.42]

$\checkmark$ : There's a particular person, unknown to the speaker, that didn't come. $\quad \exists>\neg$

\#: Nobody came.

$* \neg>\exists$

(25) Chidî shar-khí sister-go lak mán-a phi-gaido, Saldi khúp khâdu-gam.

if who-KHI sister-ACC meet-INF come-COND Saldi very happy-CF

'If Saldi meets some nun, she would be very happy.' [2016.1.131]

$\checkmark$ : There is a particular nun, unknown to the speaker, that Saldi wants to meet. $\exists>$ if \#: Meeting any nun will make Saldi happy.

$*$ if $>\exists$

That these environments are scope islands in Tiwa is evidenced by the fact that - pha indefinites cannot scope out of them, as shown in (26) and (27). They are also islands for overt syntactic movement (see Dawson to appear).

(26) [ Shar-pha phi-dom honmandé $]_{\mathrm{CP}}$ thángane cha.

who-PHA come-PST COMP correct NEG

'It's not correct that someone came.' [2016.2.42]

$\checkmark$ : Nobody came.

\footnotetext{
${ }^{9}$ Relative clauses, omitted here for reasons of space, are also scope islands and behave as expected: $-k h i$ indefinites must scope out of them.
} 
\#: There's a particular person that didn't come.

(27) Chidî shar-pha sister lak mán-a phi-gaido, Saldi khúp khâdu-gam.

if who-PHA sister meet-INF come-COND Saldi very happy-CF

'If Saldi meets some nun, she would be very happy.' [2016.1.131]

$\checkmark$ : Meeting any nun will make Saldi happy.

if $>\exists$

\#: There is a particular nun that Saldi wants to meet.

$* \exists>$ if

This obligatory, island-violating wide scope that $-k h i$ exhibits brings to mind a definite or other referring expression. Examples like (28), however, show that $-k h i$ pronouns/articles are indefinite: this sentence is not a contradiction. ${ }^{10}$ Further evidence comes from -khi's acceptability in sluicing, as (11) shows in $\S 2$ above.

Shar-khí margî rojá-ga, arô shar-khí margî rojá-ya-m.

who-KHI woman sing-PFV and who-KHI woman sing-NEG-PST

'Some woman sang, and some woman didn't sing.' [2017.2.4]

To account for - $k h i$ indefinites' scope behavior, I adopt a choice functional analysis (Winter, 1997; Reinhart, 1997; Kratzer, 1998). I propose that -khi indefinites introduce a choice function which ranges over the property denoted by their restrictor, as shown in the denotation in (29). ${ }^{11}$ This variable is subject to obligatory existential closure at the highest level (Matthewson, 1999). ${ }^{12}$

$$
\llbracket w h \text {-khi } \rrbracket=\lambda \mathrm{P} . \mathrm{f}(\mathrm{P}) \text {, where } \mathrm{f} \text { is a } \mathrm{CF}
$$

Existential closure of the choice function variable derives widest scope. This is illustrated in (30a) for the sentence in (30b) (repeated from (20) above). ${ }^{13}$

a. $\quad \exists \mathrm{f}[\mathrm{CH}(\mathrm{f}) \& \neg$ buy(Maria)(f(dress)) $]$

b. Maria inda-khí kashóng pre-ya-m.

Maria what-KHI dress buy-NEG-PST

'Maria didn't buy some dress.' [2016.1.130]

$\checkmark$ : There's a particular unknown dress Maria didn't buy.

\#: There were no dresses.

$$
\begin{array}{r}
\exists>\neg \\
* \neg>\exists
\end{array}
$$

${ }^{10} \mathrm{By}$ contrast, a bare noun in this sentence does result in a contradiction, as in (i). (Bare nouns in an external argument position in Tiwa are interpreted as definite.)

(i) \#Korkhyá lukhâi thá-ga, arô korkhyá lukhâi thá-ya-m.

child hide AUX-PFV and child hide AUX-NEG-PST

'The child hid, and the child didn't hide.' [2017.2.5]

${ }^{11}$ I assume that -khi indefinites that appear without an overt NP have an implicit restrictor.

${ }^{12}$ For the sake of simplicity I abstract away from whether this is a Skolemized choice function or not, and assume that this closure takes place at the highest level (cf. Chierchia 2001 and Schwarz 2001). The data that would bear on these questions are unclear at this stage. As far as I can tell, if necessary, these modifications would not make a difference to the pragmatic account sketched here.

${ }^{13}$ In the remainder of this paper I omit the covert assertoric operator that was included in $\S 3$ since it is not directly bear on the analysis of -khi indefinites. If it were included, it would out-scope existential closure of the choice function variable. 
Because this existential closure can occur at an arbitrary distance from the variable itself, this analysis captures -khi indefinites' island-violating scopal behavior.

\subsection{Evidence for existential closure}

Choice functional analyses do not always involve existential closure of the choice function variable. Kratzer (1998) proposes that instead the variable is left free: a seemingly wide scope indefinite is actually a specific indefinite, with the variable subject to a contextually determined assignment. ${ }^{14}$ Crucially, the value of the choice function variable does not need to be known to the hearer: instead, it is sufficient for the speaker to have a particular witness is mind. By contrast, Matthewson (1999) argues for wide existential closure of choice function variables based on data in St'át'imcets. She argues that speakers of St'át'imcets do not need to have a specific witness in mind when using a wide scope indefinite: sentences involving St'át'imcets indefinites are true and felicitous if there is any witness that fulfills the proposition. These data are explained if the variable is existentially closed.

The behavior of Tiwa's - $k h i$ indefinites favors an analysis that involves existential closure. As Matthewson argues for St'át'imcets, Tiwa speakers do not have to have a specific witness in mind in using a -khi indefinite. This is shown in the examples below. First, in (31), a -khi indefinite is used in a counterfactual conditional: Lastoi, who is unmarried, did not go to Spain, but the speaker believes that if she did, she would have married someone. The speaker does not have a particular individual in mind in making this existential claim.

$$
\begin{aligned}
& \text { Chidî Lastoi Spain-jíng lí-gaidôm, pe shar-khí-rê pháde-gam. } \\
& \text { if Lastoi Spain-ALL go-CF.COND 3SG who-KHI-COM marry-CF } \\
& \text { 'If Lastoi had gone to Spain, she would have married someone.' [2017.1.55] } \\
& \text { = There is someone such that if Lastoi had gone to Spain, she would have married him. }
\end{aligned}
$$

In (32), the speaker conveys that there is a Mizo man she would like to marry, but she doesn't have a particular one in mind. Based on the fact that she generally finds Mizo men attractive, she knows that such a man exists.

$$
\begin{aligned}
& \text { Ang shar-khí Mizo mewâ-re pháde-na as hóng-do, thêbo ang sája Mizo } \\
& \text { 1SG who-KHI Mizo man-COM marry-INF desire-IPFV but 1SG one.CL Mizo } \\
& \text { mewâ-go-bo lak mán-an' cha. Padî rí-w? } \\
& \text { man-ACC-ADD meet-NMLZ NEG how do-NEUT } \\
& \text { 'I want to marry some Mizo man, but I've never met a Mizo man before. What will I } \\
& \text { do?' [2017.2.6] } \\
& \text { = There is a Mizo man such that I want to marry him, but I don't know which one. }
\end{aligned}
$$

These data show that, at the very least, Tiwa's -khi indefinites differ from indefinites like En-

\footnotetext{
${ }^{14}$ Under her analysis, indefinites that take local scope are generalized existential quantifiers. Apparent intermediate scope examples involving island violations are instances of pseudo-scope due to a covarying argument of the choice function that is bound by a higher quantifier.
} 
glish a certain, for which the speaker does plausibly have a witness in mind. If indefinites like a certain are to be analyzed as free-variable choice functions (Kratzer, 1998; Schwarz, 2001), positing existential closure for Tiwa's - $k h i$ indefinites both captures their truth conditions and provides an explanation for their different readings. As discussed in $\S 5$ below, it is also crucial in explaining why speaker ignorance is implicated for $-k h i$ indefinites.

\subsection{Singleton domains}

The analysis of $-k h i$ indefinites provided in this section does not place any restrictions on the domain that a $-k h i$ indefinite can range over. Specifically, the choice function variable that the -khi indefinite introduces should be able to range over either a singleton or a non-singleton domain: if it ranges over a singleton, any value of $f$ will simply select the same individual. This prediction of the analysis is borne out. Unlike - pha indefinites, - $k h i$ indefinites can range over singleton domains. This is shown for the inherently singleton restrictor 'pope' in (33). Contrast this with the -pha indefinite version in (15) in $\S 3$ above. Using sharkhi in this sentence does not yield the same infelicity that using sharpha does.

Ang shar-khí Pha Khûmur-go lak mán-a lí-do.

1SG who-KHI father holy-ACC meet-INF go-IPFV

'I'm going to meet some pope.' [2017.1.28]

Another example is given in (34). Here the - $k h i$ indefinite ranges over the set of countries called Zambia (presumably a singleton set, even for someone who has never heard of it before).

$$
\begin{aligned}
& \text { Mukton [ pajíng-khî Zambia hon-a tes-a ] DP lí-ga. } \\
& \text { Mukton where-KHI Zambia say-NMLZ country-DAT go-PFV } \\
& \text { 'Mukton went to some country called Zambia.' [2017.1.141] }
\end{aligned}
$$

Context: Mukton went to Zambia. He told me, but I've never heard of Zambia before.

That -khi indefinites freely range over singleton sets rules out an analysis of their epistemic effects along the lines of that in Alonso-Ovalle and Menéndez-Benito 2010 and $\S 3$ above. Instead, these effects must be derived differently.

\section{5. $-k h i$ 's epistemic effects}

The epistemic effects associated with $-k h i$ indefinites are highly salient. While they can be canceled, given the right context (see examples (7) and (8) above), the sense that the speaker is ignorant about the witness in some way is extremely strong. Indeed, speaker translations of sentences containing a - $k h i$ indefinite frequently contain a reference to speaker ignorance. This ignorance, however, is not limited to whether the speaker can name (or otherwise clearly identify) the witness. Instead, $-k h i$ indefinites can convey speaker ignorance with respect to essentially any salient property. This range of ignorance readings is clearly shown in examples like (35). (35a) shows that this sentence cannot be felicitously followed simply with an indication that the speaker is familiar with the witness. This is expected, given -khi's epistemic effect. However, (35b) shows the speaker can in fact follow a -khi indefinite with an indication 
of familiarity, provided there is some other reason to use the epistemic indefinite. In this case, the speaker can't remember what color hair her friend has.

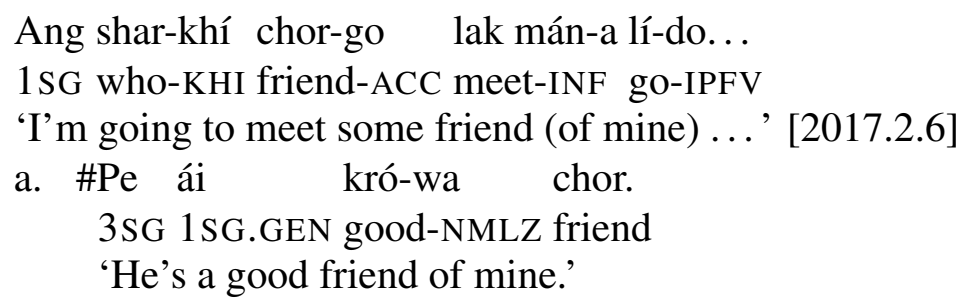

Ang shar-khí chor-go lak mán-a lí-do...

$1 \mathrm{SG}$ who-KHI friend-ACC meet-INF go-IPFV

'I'm going to meet some friend (of mine) ...' [2017.2.6]

a. \#Pe ái kró-wa chor.

3SG 1SG.GEN good-NMLZ friend

'He's a good friend of mine.'

b. Pe ái kró-wa chor, thêbo ang pe-ne khuní-ne ajâr-go

3SG 1SG.GEN good-NMLZ friend but 1SG 3SG-GEN hair-GEN color-ACC

plaw-ga. (Pegâne angá pe-go pishár-a sâsti hóng-o.)

forget-PFV therefore $1 \mathrm{SG}$.DAT $3 \mathrm{SG}-\mathrm{ACC}$ search-NMLZ trouble COP-NEUT

'He's a good friend of mine, but I forgot what color his hair is. (So I'm going to have trouble searching for him.)'

This freedom of what kind of ignorance - khi can convey is also evident in the singleton domain examples like (36). This sentence is felicitous in a case in which the speaker knows who the Indian Prime Minister is (in the sense that she knows he is the man called Narendra Modi), but she has never met him before.
Ang shar-khí India-ne PM-go lak mán-a lí-do.
1SG who-KHI India-GEN PM-ACC meet-INF go-IPFV
'I'm going to meet some Indian Prime Minister.' [2016.2.80]
$\checkmark$ : The speaker hasn't met him before, but she knows he's Narendra Modi.

A similar range of ignorance effects are conveyed with the inherently singleton examples in $\S 4.2$. The pope example in (33) conveys that the speaker is unfamiliar with the pope, whether that is because she has never met him, or because she doesn't know who he is. In (34), while the speaker clearly knows the name of the country Zambia, she is otherwise completely unfamiliar with it. The generalization in all the examples is that the speaker must be ignorant about some contextually relevant property of the witness, whether that's his hair color, his name, or something else. ${ }^{15}$

For Aloni and Port (2015), this variability in kinds of speaker ignorance is central to understanding epistemic indefinites. The key observation is that what it means to identify a witness will vary in different contexts. That is, in one context it might be sufficient to be able to name the witness without knowing anything else about it, but in another it might be sufficient to describe a witness, without knowing its name. Couched in conceptual covers (Aloni, 2001), such as naming, ostension, and description, Aloni and Port's analysis is that epistemic indefinites are indefinites that are only licensed when there is a shift in the conceptual cover being used to identify the witness. This style of analysis captures a key fact of Tiwa's - khi indefinites: in

\footnotetext{
${ }^{15}$ Like Japanese - $k a$ indefinites (Alonso-Ovalle and Shimoyama, 2014), the $w h$-base of the indefinite plays a role in the kind of ignorance that is conveyed: for inanimates, inda-khi "what-KHI" conveys ignorance with respect to type of the witness, while pakhâ-khi "which-KHI" conveys ignorance with respect to token. This seems to be independent of the variation in what counts as speaker ignorance in a given context.
} 
most cases, -khi indefinites convey that the speaker cannot identify the witness by some salient property. Aloni and Port's analysis treats the epistemic component of the indefinite as a felicity condition associated with the lexical item itself. Given the data in $\S 2$ above, I propose that we treat the epistemic effects associated with $-k h i$ indefinites as a conversational implicature, rather than a felicity condition, but draw on Aloni and Port's insights regarding how the witness is identified in a given context.

Instead of positing a felicity condition, I suggest that ignorance with respect to a salient property of the witness is implicated by means of the choice functional nature of $-k h i$ indefinites. A choice function is a function that picks out an individual from a set. That choice function could reflect any property. For example, as applied to the set of my friends, it could reflect the property of having red hair. It could also reflect the property of being named Narendra Modi. Depending on the set in question, the property that will uniquely select an individual will vary: in a set otherwise of black-haired individuals, the function $\lambda x$.has-red-hair $(x)$ will select my red-headed friend Monbor. But in a set of red-haired individuals, a different function will be needed. In $\S 4$, I proposed that $-k h i$ indefinites are choice functional in order to derive their scope facts. Here, I suggest that this choice functional nature, combined with existential closure of the choice function variable, is exactly how their epistemic effects arise.

In all the cases discussed here, the speaker could have used a definite (or other referring expression) in place of a $-k h i$ indefinite to make a stronger statement. She did not. In using an indefinite (that is, in existentially quantifying) she already potentially implicates ignorance, to the extent that any existential quantification does (including other non-epistemic indefinites like English $a$ ). But the epistemic effects that $-k h i$ gives rise to are stronger than this sort of weak ignorance. Crucially, a -khi indefinite is not the only way to existentially quantify in Tiwa. Instead, the speaker could have used either a plain indefinite or a -pha indefinite. Consider the following sentence, repeated in part from (1) above:
a. Shar-khí phi-dom.
who-KHI come-PST
'Someone came.' [2017.1.81]
b. $\quad \exists \mathrm{f}[\mathrm{CH}(\mathrm{f}) \&$ came $(\mathrm{f}($ human $))]$

Instead of uttering (37a), the speaker could have uttered either (38a) or (39a), which would have resulted in (near) equivalent truth conditions.
a. Sája líbing phi-dom.
one.CL person come-PST
'A person came.' [2017.1.81]
b. $\exists x[\operatorname{human}(\mathrm{x}) \& \operatorname{came}(\mathrm{x})]$
a. Shar-pha phi-dom. who-PHA come-PST
'Some person came.' [2017.1.81]
b. $\exists x[f($ human $)(x) \&$ came(x)], where $\mid f($ human $) \mid>1$


Both these alternate strategies involve existential quantification directly over individuals. (The difference between the two, recall, is that -pha presupposes a non-singleton domain, while the plain indefinite has no domain requirements.) Where these alternatives involve direct existential quantification over individuals, a - $k$ hi indefinite involves a higher order quantification: existential quantification over choice functions that range over individuals. A listener might wonder why the speaker has chosen this indirect route, where obvious alternatives were available.

Importantly, this reasoning holds in different scope scenarios: the plain indefinite can also (but need not) take island-violating wide scope, allowing it to serve as a competitor to $-k h i$ indefinites in all cases. This wide scope is shown in (40) for a conditional island (compare to the -khi indefinite in (25) and the island-bound -pha indefinite in (27)).

Lastoi sája ticher-go pasé-gaidô, lí-w.

Lastoi one.CL teacher-ACC speak-COND go-NEUT

'If Lastoi talks to a teacher, she will leave.' [2017.1.156]

$\checkmark$ : Lastoi needs to get permission from a particular teacher in order to leave school early; no other teacher can grant her permission.

I suggest that the use of a choice functional indefinite explicitly highlights different ways of selecting an individual from a set. That is, invoking choice functions brings up the various possible ways of selecting the individual: it could be by name, by ostension, or even by hair color. Importantly, the speaker existentially quantifies over the choice function variable introduced by $-k h i$. A sentence containing a - khi indefinite literally asserts that there is a way of selecting an individual from the domain such that the predicate holds of that individual. Since the speaker didn't use a definite (or otherwise specify how the individual can be selected), this implicates ignorance about not the witness itself, but the way that the witness is to be selected.

This account crucially relies on existential quantification over the choice function variable. In $\S 5$ I contended that there is evidence independent of epistemic effects to posit this closure in Tiwa, namely, the speaker does not have to have a particular witness in mind. This contrasts with another wide scope indefinite, English a certain, which Kratzer (1998) analyzes as choice functional without existential closure. The behavior of a certain fits with this analysis: in using a certain the speaker does indeed seem to have a particular individual in mind. A certain also does not result in the kinds of ignorance effects see above for Tiwa's - $k h i$ indefinites. If $-k h i$ indefinites do involve obligatory existential closure, while the choice function variable introduced by a certain is left free, these differences are straightforwardly explained. ${ }^{16}$

The epistemic effects associated with - $k h i$ indefinites, then, plausibly arise as a natural consequence of their narrow semantics in competition with other elements in the system. The wide range of ignorance readings is a result of the choice function variable that -khi introduces. This type of competition does not, however, result in a more familiar quantity implicature: both $-k h i$ indefinites and their more direct indefinite alternatives result in equally strong statements. Instead, the result of this competition is closer to a manner implicature.

\footnotetext{
${ }^{16}$ This suggestion is related to Schwarz's (2001) observation that not all wide scope indefinites behave the same way, and that a unified analysis is not necessarily desirable.
} 


\section{Conclusion}

In this paper, I have provided a description of Tiwa's two series of epistemic indefinites. One of these series, the - pha indefinites, bears an anti-singleton constraint similar to Spanish algún and likewise shows similar, cancelable epistemic effects. Tiwa's - pha indefinites thus provide cross-linguistic support for Alonso-Ovalle and Menéndez-Benito's (2010) account of how the epistemic effects of Spanish algún arise (i.e., that they are related to domain requirements). Tiwa's other series of epistemic indefinites, the - $k h i$ series, always take widest scope, and are best analyzed as introducing a choice function that is existentially closed above other operators. I suggest that the epistemic effects associated with Tiwa's wide scope indefinites arise as a direct result of this quantification over choice functions, in competition with Tiwa's other indefinites (and with stronger, definite alternatives). This account relies on the understanding that -khi indefinites involve a higher order quantification over functions, rather than individuals, which leads to an ignorance implicature about the way an individual can be identified. There is a close connection between this higher order ignorance implicature, and Aloni and Port's (2015) felicity conditions which involve shifts in conceptual covers.

\subsection{Crosslinguistic predictions}

The account of -khi indefinites' epistemic component sketched in $\S 5$ makes a key crosslinguistic prediction. Namely, if the epistemic effects arise as a consequence of general Gricean reasoning, we would expect to find them in any language with a sufficiently similar system. In the remainder of this conclusion, I will provide an initial evaluation of this prediction.

Choice functional analyses of wide scope indefinites have been proposed for various languages. These include English a certain (Kratzer, 1998), the wide scope reading of English $a$ (Reinhart, 1997; Kratzer, 1998), ${ }^{17}$ St'át'imcets indefinites (Matthewson, 1999), and the Russian -to series (Yanovich, 2005), among others. However, not every wide scope indefinite triggers the kind of salient epistemic effects found with Tiwa's -khi indefinites. Among the choice functional indefinites listed here, only the Russian -to series has been reported to convey speaker ignorance (Kagan, 2011). I will consider each of these in turn, beginning with English, and suggest how the presence or absence of epistemic effects is compatible with the account sketched above.

First, as discussed in $\S 5$ above, if English a certain is choice functional, but lacks existential closure of the choice function variable (Kratzer, 1998), we expect there to be no ignorance effect. The speaker has not existentially quantified over choice functions (which implicates ignorance about the witness to that quantification), but left the variable free. As Kratzer notes, it seems sufficient in this case for the speaker to have a specific witness in mind. If this is correct, we expect a certain to not give rise to speaker ignorance. The situation is more complicated for the plain English indefinite $a$. Under a Kratzer-style analysis, the choice function variable that $a$ introduces (when it takes exceptional wide scope) is left free. If this is the case, then again we do not expect ignorance effects. If, however, the choice function variable is existentially closed

\footnotetext{
${ }^{17}$ Reinhart (1997) analyzes all instances of English $a$ as choice functional, with existential closure occuring at different levels. Kratzer treats $a$ as ambiguous between a generalized quantifier and choice functional indefinite.
} 
in these cases (Reinhart, 1997), then we might expect ignorance effects to arise. It is however possible that wide scope English $a$ is not a choice functional indefinite at all, but rather, as Schwarzschild (2002) proposes, that exceptional wide scope might arise solely through domain restriction to a singleton (i.e. exceptional scope $a$ still involves quantification directly over individuals). If his account is correct, then the absence of ignorance effects with wide scope $a$ are expected.

In contrast to English a certain, St'át'imcets choice functional indefinites do seem to involve existential closure of the choice function variable (Matthewson, 1999), but do not seem to give rise to speaker ignorance effects. Matthewson does not explicitly discuss epistemic effects associated with St'át'imcets wide scope indefinites. Such effects are also not reflected in the various speaker comments associated with example sentences, or in the contexts that allow for a felicitous use of the indefinites. While this in itself does not entail that such epistemic effects are not present, it is suggestive of a difference between Tiwa's -khi indefinites and St'át'imcets' wide scope indefinites. Exploring the scope and other properties of Tiwa's - $k h i$ indefinites lead to consistent consultant commentary (independently, by multiple consultants) on their epistemic effects, to the point where sharkhídi "someone" [2016.2.52] was offered as a translation for the English word "stranger". Further, Matthewson discusses data that suggest that the speaker does not convey ignorance with respect to the witness in using a choice functional indefinite in St'át'imcets, as in (41).

Context: Rose goes to the store and asks the salesperson for a copy of the book False Crow. The salesperson gives her a book in a bag, and Rose pays for it. When she gets home, she tells her daughter:
a. tecwp-kán [ta púkw-a]
buy-1SG.SUBJ [DET book-DET]
'I bought a book.'

(Matthewson, 1999: 124)

St'át'imcets wide scope indefinites then are both choice functional with existential closure, and seem not to convey speaker ignorance with respect to the witness. This, however, does not pose a problem for the account given above for Tiwa, which is based in general Gricean reasoning, due to differences in the overall system of determiners. Specifically, Tiwa's choice functional indefinites give rise to ignorance implicatures due to competition with the plain indefinite: a generalized existential quantifier that can occur in the same environments as $-k h i$ indefinites. St'át'imcets lacks such a competitor: the only non-choice functional determiner $(\mathrm{ku})$ is licensed only under negation, a modal, a conditional operator, or a question operator (Matthewson 1999). It takes obligatory narrow scope with respect to these operators, and is not licensed in a plain declarative. Consequently, St'át'imcets choice functional indefinites are never in competition with a plain indefinite. ${ }^{18}$ St'át'imcets thus provides a case of a language which has the same kind of choice functional indefinite as Tiwa (i.e. one that involves existential quantification), but does not give rise to ignorance implications due to differences in the set of competitors.

Finally, we are left with the question of whether there are languages in addition to Tiwa that

\footnotetext{
${ }^{18}$ As Matthewson (1998) argues, St'át'imcets also lacks definite determiners.
} 
have the necessary conditions (that is, both existentially closed choice functional indefinites, and suitable competitors) that show similar effects. While in-depth further research will be necessary to determine whether this is the case, I want to conclude by discussing a possible candidate. Russian has a series of wide scope indefinite determiners (the -to series) that are similar to those in Tiwa: they take exceptional wide scope. Yanovich (2005) analyzes these indefinites as choice functional (specifically providing a compositional account of the internal structure of the determiners in a Hamblin semantics). He adopts a Kratzer-style analysis in which the choice function variable is left free, rather than existentially closed. While this may be the correct analysis for -to indefinites, it's worth noting that these indefinites do give rise to a strong sense of speaker ignorance. Kagan (2011) provides a detailed description of these ignorance effects, framing them in terms of speaker identifiability: in using a -to indefinite, the speaker has signaled that she cannot identify the witness. Importantly, what counts as identifiability is highly context dependent, as Kagan (2011: 60) notes: "In some cases, knowing a person's name or how the person looks is sufficient. In others, knowledge of additional details is required." Kagan provides an analysis of the ignorance effects of -to pronouns as a conventional implicature in terms of scope relative to quantification over possible worlds. While a more detailed comparison between Russian -to indefinites, Tiwa -khi indefinites, and the two systems as a whole remains to be done, it is possible that Russian provides another instance of a Tiwa-like wide scope epistemic indefinite.

\section{References}

Aloni, M. (2001). Quantification under conceptual covers. Ph. D. thesis, University of Amsterdam.

Aloni, M. and A. Port (2015). Epistemic indefinites and methods of identification. In L. AlonsoOvalle and P. Menéndez-Benito (Eds.), Epistemic Indefinites: Exploring Modality Beyond the Verbal Domain, pp. 117-140. Oxford: Oxford University Press.

Aloni, M. and R. van Rooij (2004). Free choice items and alternatives. In Proceedings of the KNAW academy colloquium: Cognitive foundations of interpretation, pp. 5-6.

Alonso-Ovalle, L. and P. Menéndez-Benito (2010). Modal indefinites. Natural Language Semantics 18, 1-31.

Alonso-Ovalle, L. and P. Menéndez-Benito (2013). Two views on epistemic indefinites. Language and Linguistic Compass 7(2), 105-122.

Alonso-Ovalle, L. and P. Menéndez-Benito (2015). Epistemic indefinites: An overview. In L. Alonso-Ovalle and P. Menéndez-Benito (Eds.), Epistemic Indefinites: Exploring Modality Beyond the Verbal Domain, pp. 1-27. Oxford: Oxford University Press.

Alonso-Ovalle, L. and J. Shimoyama (2014). Expressing ignorance in the nominal domain: Japanese Wh-ka. In R. Santana-Labarge (Ed.), Proceedings of the West Coast Conference on Formal Linguistics 31, pp. 11-20. Somerville: Cascadilla Press.

Chierchia, G. (2001). A puzzle about indefinites. In C. Cecchetto, G. Chierchia, and M. T. Guasti (Eds.), Semantic interfaces: reference, anaphora and aspect, pp. 51-89. Stanford: CSLI.

Chierchia, G. (2006). Broaden your views. Implicatures of domain widening and the 'logicality' of language. Linguistic Inquiry 37(4), 535-590.

Dawson, V. (to appear). Tiwa indeterminates and NP restriction in a Hamblin semantics. In 
S. Bhatia and D. Chacon (Eds.), Proceedings of FASAL 7.

Fălăuş, A. (2014). (Partially) Free choice of alternatives. Linguistics and Philosophy 37, 121173.

Farkas, D. F. (2002). Extreme non-specificity in Romanian. In C. Beyssade, R. Bok-Bennema, F. Drijkoningen, and P. Monachesi (Eds.), Romance Languages and Linguistic Theory 2000, pp. 127-151. Amsterdam: John Benjamins.

Heim, I. (1991). Artikel und Definitheit. In A. von Stenchow and D. Wunderlich (Eds.), Semantics: An International Handbook of Contemporary Research. Berlin: de Gruyter.

Jayez, J. and L. M. Tovena (2006). Epistemic determiners. Journal of Semantics 23(3), 217250.

Jayez, J. and L. M. Tovena (2007). Evidentiality and determination. In A. Grønn (Ed.), Proceedings of Sinn und Bedeutung 12, pp. 271-286.

Joseph, U. (2014). Tiwa-English Dictionary with English-Tiwa Index. Shillong: Don Bosco Centre for Indigenous Cultures.

Kagan, O. (2011). On speaker identifiability. Journal of Slavic Linguistics 19(1), 47-84.

Kratzer, A. (1998). Scope or pseudoscope? Are there wide-scope indefinites? In S. Rothstein (Ed.), Events and Grammar, pp. 163-196. Dordrecht: Kluwer Academic Publishers.

Kratzer, A. and J. Shimoyama (2002). Indeterminate pronouns: The view from Japanese. In Y. Otsu (Ed.), The Proceedings of the Third Tokyo Conference on Psycholinguistics. Tokyo: Hituzi Syobo.

Matthewson, L. (1998). Determiner Systems and Quantificational Strategies: Evidence from Salish. The Hague: Holland Academic Graphics.

Matthewson, L. (1999). On the interpretation of wide-scope indefinites. Natural Language Semantics 7, 79-134.

Reinhart, T. (1997). Quantifier scope: How labor is divided between QR and choice functions. Linguistics and Philosophy 20(4), 335-397.

Schwarz, B. (2001). Two kinds of long distance indefinites. In R. van Rooy and M. Stokhof (Eds.), Proceedings of the Thirteenth Amsterdam Colloquium, pp. 192-197. Amsterdam University.

Schwarzschild, R. (2002). Singleton indefinites. Journal of Semantics 19, 289-314.

Šimík, R. (2015). Epistemic indefinites under epistemic modals in Czech. In G. Zybatow, P. Biskup, M. Guhl, C. Hurtig, O. Mueller-Reichau, and M. Yastrebova (Eds.), Slavic grammar from a formal perspective: Proceedings of the 10th Anniversary Conference on Formal Description of Slavic Languages (FDSL 10), Frankfurt am Main, pp. 425-442. Peter Lang.

Simons, G. F. and C. D. Fennig (Eds.) (2017). Ethnologue: Languages of the World, Twentieth edition. Dallas, Texas: SIL International. Online edition: http://www.ethnologue.com.

Winter, Y. (1997). Choice functions and the scopal semantics of indefinites. Linguistics and Philosophy 20(4), 399-467.

Yanovich, I. (2005). Choice-functional series of indefinite pronouns and Hamblin semantics. Semantics and Linguistic Theory 15, 309-326.

Zamparelli, R. (2007). On singular existential quantifiers in Italian. In I. Comorovski and K. von Heusinger (Eds.), Existence: Semantics and Syntax, pp. 293-328. Springer. 